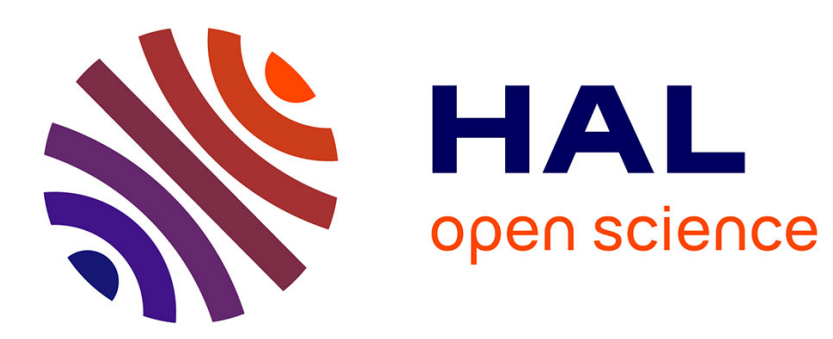

\title{
Study of a liquid-gas mixing layer: Shear instability and size of produced drops
}

Sylvain Marty, Jean-Philippe Matas, Alain H. Cartellier

\section{To cite this version:}

Sylvain Marty, Jean-Philippe Matas, Alain H. Cartellier. Study of a liquid-gas mixing layer: Shear instability and size of produced drops. 3e colloque INCA, Initiative en Combustion Avancée, Nov 2011, Toulouse, France. pp.1. hal-00704327

\section{HAL Id: hal-00704327 \\ https://hal.science/hal-00704327}

Submitted on 5 Jun 2012

HAL is a multi-disciplinary open access archive for the deposit and dissemination of scientific research documents, whether they are published or not. The documents may come from teaching and research institutions in France or abroad, or from public or private research centers.
L'archive ouverte pluridisciplinaire HAL, est destinée au dépôt et à la diffusion de documents scientifiques de niveau recherche, publiés ou non, émanant des établissements d'enseignement et de recherche français ou étrangers, des laboratoires publics ou privés. 


\title{
Study of a liquid-gas mixing layer: Shear instability and size of produced drops
}

\author{
Sylvain Marty, Jean-Philippe Matas Alain Cartellier \\ Laboratoire des Ecoulements Géophysiques et Industriels (LEGI), \\ CNRS-Université de Grenoble, BP53 38041 Grenoble Cedex 9 \\ Received ${ }^{* * * * *}$; accepted after revision +++++ \\ Presented by £££££
}

\begin{abstract}
We study experimentally the atomization of a liquid sheet by a parallel gas flow, in order to understand the conditions of destabilization of the liquid sheet and the conditions of drop creation. We study in particular the regimes at low M (ratio of gas/liquid dynamic pressures), to test the scaling law proposed and validated in previous studies at large $M(M=16)$.

The inviscid stability analysis of the system is carried out with a new velocity profile taking into account the wake of the splitter plate (zero speed at the level of the splitter plate): the influence of liquid velocity on the shear instability frequency turns out to be significantly stronger for this type of velocity profile than for classical ones.

An asymptotic study of the dispersion relation leads to a new scaling law giving the wavenumber of the shear instability as a function of gas velocity $U_{g}$, with a corrective term in $M$. Frequency measurements carried out by a spectral method show a good agreement with this corrected law.

We investigate by way of optical probe measurements the size distribution of produced drops downstream. The difficulty of these measurements resides in the decrease of the numerical drop flux at low $M$. Results obtained for the mean chord are consistent with previous studies. Diameter distributions are obtained from chord distributions with a numerical conversion procedure.
\end{abstract}

To cite this article: S. Marty, J.P. Matas, A. Cartellier, C. R. Mecanique 333 (2011).

\section{Résumé}

Etude d'une couche de mélange liquide gaz : instabilité de cisaillement et taille de gouttes produites

Nous étudions expérimentalement l'atomisation d'une nappe liquide par un courant parallèle gaz, afin de comprendre les conditions de déstabilisation de la nappe liquide et les conditions de formation de gouttes. Nous étudions en particulier les

Article submitted to $3 r$ INCA Colloquim


régimes de faible $\mathrm{M}$ (rapport de pression dynamique gaz/liquide), afin de tester les lois d'échelle mises en évidence lors d'études précédentes et validées sur un régime à grand $M(M=16)$.

L'analyse de stabilité inviscide du système est menée avec un nouveau profil de vitesse prenant en compte le sillage de la plaque séparatrice (vitesse nulle au niveau de la plaque de séparation ) : l'influence de la vitesse de phase liquide sur la fréquence de l'instabilité de cisaillement est significativement plus forte pour ce type de profil de vitesse que pour les profils classiques. Une étude asymptotique de la relation de dispersion permet de trouver une nouvelle loi d'échelle reliant le nombre d'onde du mode le plus instable à la vitesse gaz $U_{g}$, avec un correctif en $M$. Les mesures de fréquence réalisées par une méthode spectrale montrent un bon accord avec cette loi d'échelle corrigée.

Connaissant les mécanismes en amont nous nous intéressons également aux distributions de taille de gouttes en aval, mesurées par sonde optique. La diminution du flux numérique de goutte et le changement des plages de vitesse des fluides à faible $M$ rendent les mesures plus complexes. Les résultats sur les cordes moyennes mesurées sont cohérents avec les études précédentes. Le passage des histogrammes de cordes aux histogrammes de diamètre fait appel à des méthodes numériques très sensibles aux valeurs extrêmes de cordes.

Pour citer cet article: S. Marty, J.P. Matas, A. Cartellier, C. R. Mecanique 333 (2011).

Key words: Keyword1 from list; Keyword2 ; Keyword3

Mots-clés : couche de mélange liquide gaz; analyse de stabilité; distributions de taille de gouttes

\section{Assisted atomisation for low dynamic pressure ratio}

Modern turbojet or cryogenic engines use two-phases nozzles to feed their combustion chamber with fuel and comburant. This kind of injection turns a liquid flow into a homogeneous spray under the action of a fast gas stream. A good quality of this mixture is needed to optimize combustion. Several geometries exist for these injectors (gaz or fluid centered, with or without recess length) with various diameter and length Our experimental set-up models an injector with an infinite diameter and a large liquid flow thickness (figure 1). With this geometry we avoid any 3D instability, like the flapping instability of a round liquid jet. Our injector is composed of two parallel channels: channel below is fed with water from a overflowing tank. Liquid velocity is in the range 0.1 to 1 $m . s^{-1}$ The upper channel receives a gas stream from a compressor. The maximum gas velocity is near $100 \mathrm{~m} . \mathrm{s}^{-1}$. In order to limit velocity perturbations,

Email address: Sylvain.Marty@hmg.inpg.fr.fr (Sylvain Marty). 
honey combs are inserted in each channel, a porous plate in the gas one, and each channel ends with a smooth convergent profile (figure 1). In addition to the geometrical characteristics of the nozzle and fluid properties we have two main parameters controlling the injection: gas velocity $U_{g}$ and liquid velocity $U_{l}$. The dynamic pressure ratio $M$ can be used in place of either velocity.// Previous studies carried out on this set-up have highlighted successive mechanisms of destabilization $[1,2,3]$. First a shear instability controlled by the gas vorticity thickness has been clearly identified: this Kelvin-Helmholtz type instability induces longitudinal waves. On the crest of these waves a transversal instability takes place, similar to a Rayleigh-Taylor instability (it is caused by the acceleration of the waves). The transversal perturbations then turn into ligaments by elongation, and eventually break into droplets (see [1] and Marmottant and Villermaux [2]).

One of the most notable result evidenced by Raynal is the dependency of the wavenumber $k$ of the most amplified mode of the axial instability on the gas flow vorticity thickness $\delta_{g}$ (equation 1$)$ :

$$
k \approx 1.5 \sqrt{\frac{\rho_{l}}{\rho_{g}}} \frac{1}{\delta_{g}}
$$

Wave velocity can be estimated from Dimotakis velocity $U_{c}$, deduced from stress continuity[4]:

$$
U_{c}=\frac{\sqrt{\rho_{l}} U_{l}+\sqrt{\rho_{g}} U_{g}}{\sqrt{\rho_{l}}+\sqrt{\rho_{g}}}
$$

Frequency of the most unstable mode can then finally be approximated as

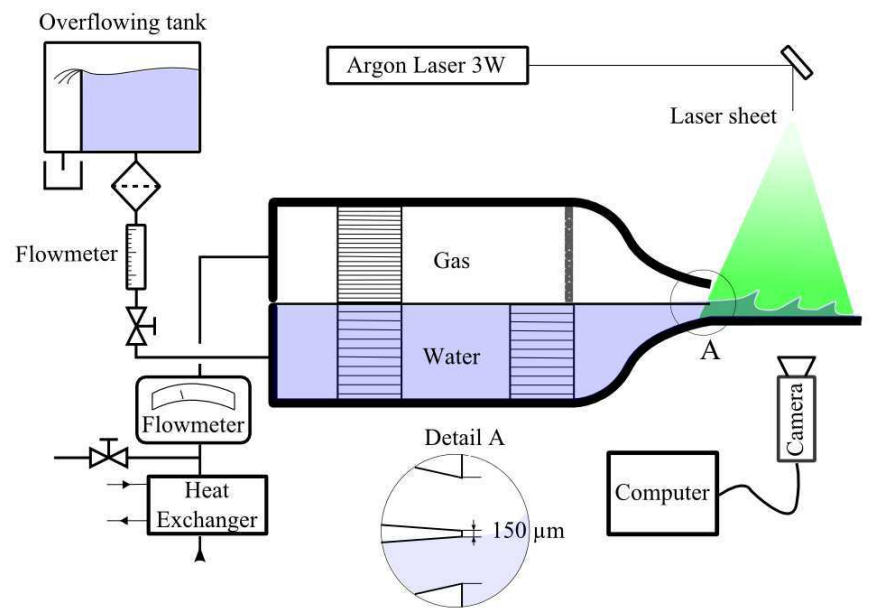

Figure 1. Sketch of the experimental set-up. 


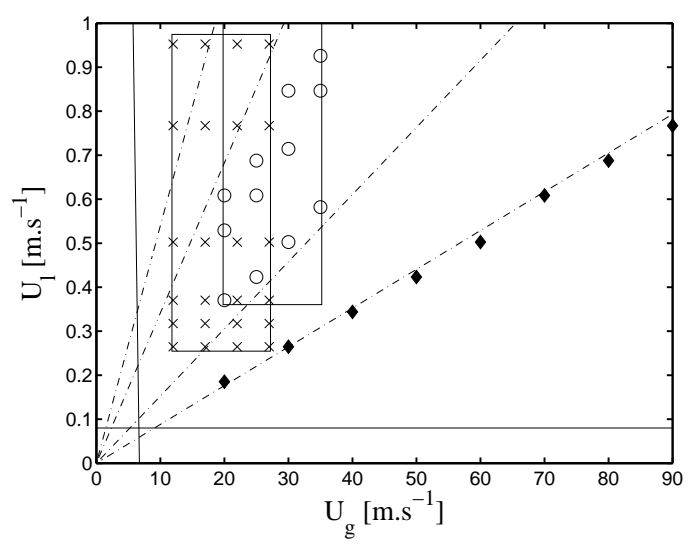

Figure 2. Map of experimental points

$\omega=k U_{c}$.

Hong [3] and Ben Rayana [5] have used the same set-up used by Raynal, but have focused on a constant $M=16$ ratio (black diamond series of figure 2). These conditions are relevant to cryotechnic engines. In the present study, we vary $M$ to investigate the influence of this parameter on the instability. The crosses on figure 2 correspond to the frequency measurements of the present study. We will compare the predicted frequency with the measured one. The circle series corresponds to the experimental conditions for which droplet size distributions were obtained. A minimum flux of drops is needed in order to ensure a good resolution of the chord pdf: this is why size distributions could not be measured for the same conditions for which frequencies were measured. Finally chord distributions will be presented in section 4 .

\section{Asymptotic analysis: influence of a velocity deficit}

One of the difficulty in the stability analysis is the choice of a relevant velocity profile for both flows. For their studies Raynal [1] and Marmottant and Villermaux [2] used the final profile far downstream the injection (see figure 3), but neglected the vorticity thickness $\delta_{l}$ in the liquid flow [1]. They also showed that in the case of an invicid analysis, the smooth velocity profile (solid line of figure 3) can be modelled by a linear one (dashed line of figure 3). A new approach, by Matas et al.[6], takes into account the wake due to the splitter plate: there is a velocity deficit right after the splitter plate. The stability analysis is therefore carried out with the dashed profile represented at the end of the splitter plate. Figure 4(a) present the dimensionless frequency obtained with both profiles (dashed line without a deficit, and solid line with a deficit), as a function of $M$. The gap between the two profiles becomes larger for low $M$ : the frequency is strongly underestimated by the classical analysis for low $M$. The same effect is observed for the dimensionless growth rate, see figure 
$4(b)$.

In order to generalize the prediction of equation 1 when the velocity deficit is included, an asymptotic analysis is carried out on the dispersion relation around the unstable mode. It is assumed that $M$ of order 1 or larger, $\rho_{g} / \rho_{l}<<1$ and that $k$ is proportional to $\sqrt{\rho_{l} / \rho_{g}}$. The resulting wavenumber and frequency are:

$$
\begin{aligned}
& k=\left(\sqrt{2}+\frac{3}{2} M^{-1 / 2}\right) \sqrt{\frac{\rho_{g}}{\rho_{l}}} \frac{1}{\delta_{g}} \\
& \omega_{r}=\frac{\rho_{g}}{\rho_{l}} \frac{U_{g}}{\delta_{g}}\left(1+\frac{5}{2} \sqrt{2} \cdot M^{-1 / 2}\right)
\end{aligned}
$$

This results introduce a corrective term in $M$ to the prediction of Raynal [1], Marmottant and Villermaux [2]. In order to test both predictions, frequency was measured for $M$ smaller than 10, i.e. when the corrective term is not negligible.

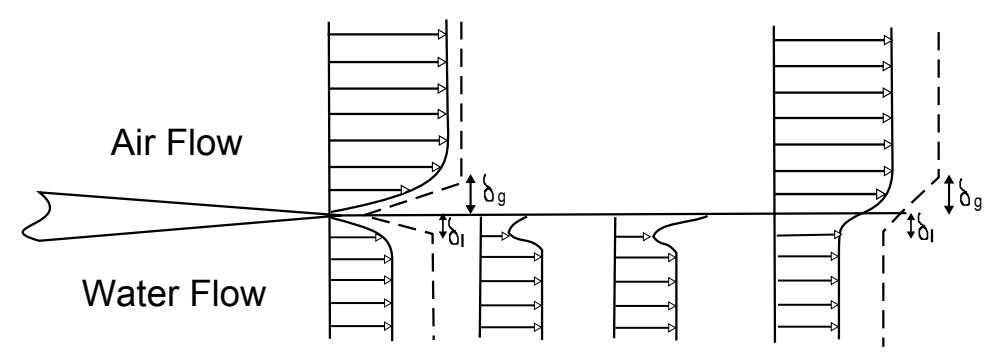

Figure 3. Downstream variations of the velocity profile.

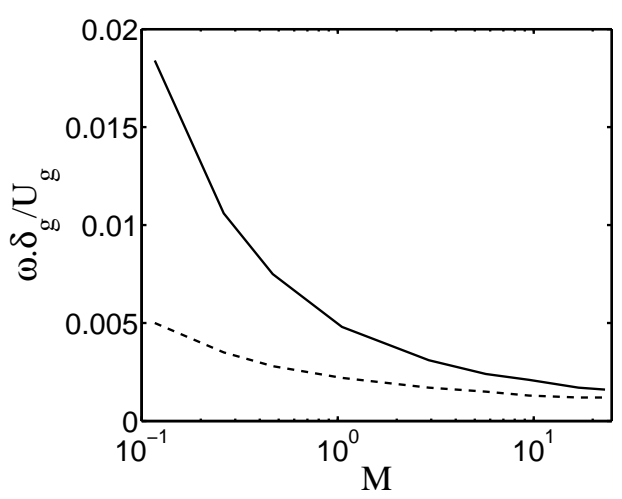

(a)

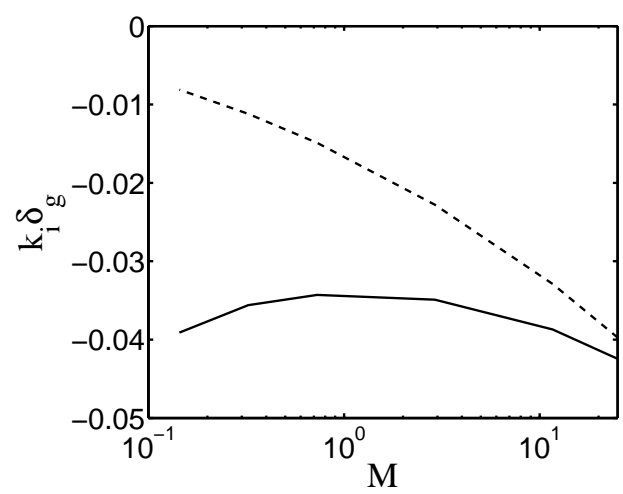

(b)

Figure 4. 


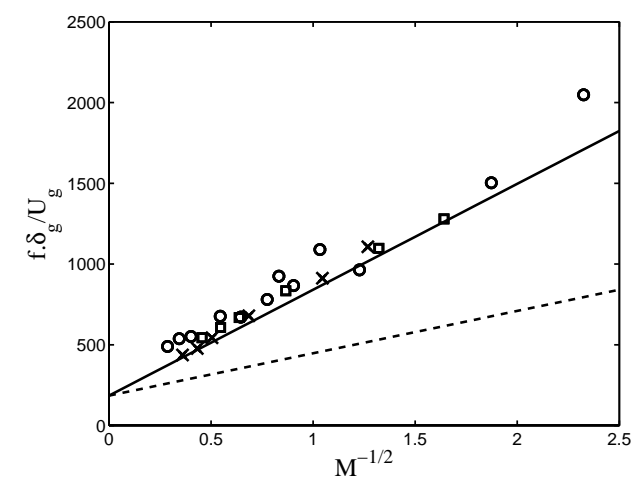

(a) Dimensionless frequency as a function of $M$

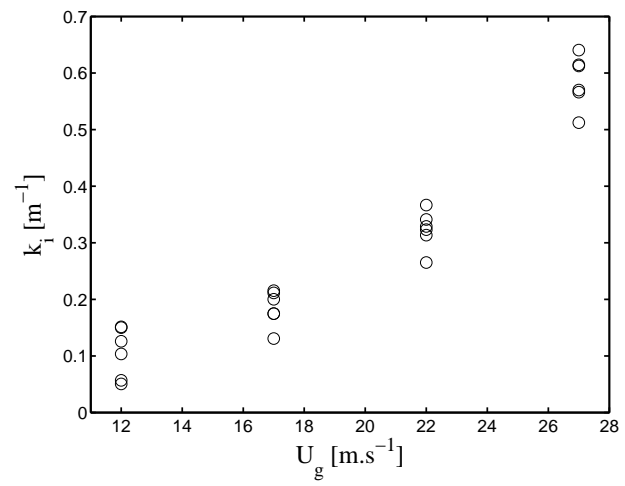

(b) Dimensionless growthrate as a function of $U_{g}$

Figure 5. Shear instability frequency (a) and growthrate (b): comparison of experiments with the asymptotic laws derived from the analysis.

\section{$3 \quad$ Frequency and growthrate measurements}

In order to determine the frequency of the most amplified Kelvin-Helmholtz mode, we use a LIF method. Fluorescein is mixed in the liquid phase, a longitudinal section of the flow is made with an Argon laser, and a high speed camera (Phantom V2) records flow motion in this section. Post treatment of the movie uses a Sobel filter to localize the water surface. We therefore obtain the position $h$ of surface as a function of time and downstream position: $h=f(x, t)$. A Fourier transform of $h$ (modified by Welch method) yields the desired frequency, see figure 5(a). The dimensionless frequency is plotted as a function of $M^{-1 / 2}$. Experimental series $\circ, \square, \times$ and $\bullet$ display each gas velocity used, respectively 12, 17, 22 and $27 \mathrm{~m} / \mathrm{s}$. Dotted line corresponds to the prediction without a deficit, and solid line to the prediction of equation 4. Experimental points are collapsed around the solid line for all $M$, in agreement with the analysis where the deficit is included. From the interface position $h=f(x, t)$ we can also draw the variations of wave amplitude downstream the injector. Some processing has to be carried out, see reference [6], in particular to exclude rare events, after which the spatial growthrate $k_{i}$ of the longitudinal instability can be obtained. Figure 5(b) shows $k_{i}$ as a function of gas velocity. The growthrate is mainly a function of gas velocity, and not $M$ : this behaviour is not predicted by the inviscid stability analysis. We believe it results from the large amplitude of the waves, which will itself impacts gas flow, a non linear mechanism not included in the stability analysis. 


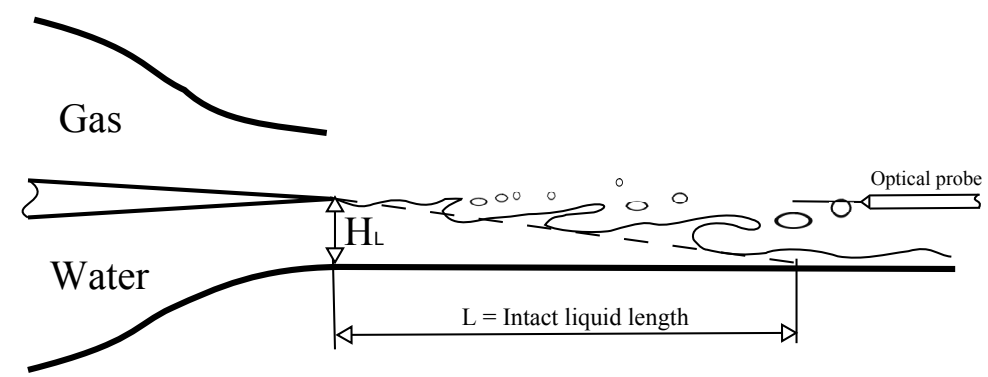

Figure 6. Relative position of the probe to the spray

\section{Droplet size and flux measurements}

The previous section has evidenced a significant sensitivity of the axial instability characteristics to the $M$ parameter. The question to be considered now is whether this parameter also alters the size or the flux of the drops produced at the last step of the atomization process. We have therefore gathered information on drops for flow conditions close to those for which frequency and growthrate have been investigated. Droplet size and fluxes have been measured with a monofiber optical probe: detailed information about this sensor and the associated signal processing and post-processing can be found in references [7] and [8]. For the present study, we used an optical probe with a $30 \mu \mathrm{m}$ sensitive length so that unbiased detection is expected for drops above $10-12 \mu m([7])$. Note that we cannot exactly cover the same range of conditions as those considered in the previous section. Indeed, for gas velocities below about $20 \mathrm{~m} . \mathrm{s}^{-1}$, the flux of drops remains very weak and the convergence of the statistics would imply very long acquisition times. In addition, at low gas velocities, the probe dewetting time becomes quite long and may alter the signal quality. Therefore, drop characteristics have been analysed for gas velocities equal to and above $20 \mathrm{~m} . \mathrm{s}^{-1}$. This problem is solved by adapting signal processing parameters for each conditions, and by verifying carefully the consistency of each signal. As Hong (2003) has shown that the spatial variations of the measured flux are quite strong [3], care was also taken, when varying $M$, to collect data at the same position relative to the flow for all conditions (figure 6) when varying M. Along the vertical axis, the probe is aligned with the splitter splate, and its downstream position is located at the end of the theoretical liquid intact length $L$. The latter has been shown (Raynal 1997 [1]) to vary as: $\frac{L}{2 H_{1}} \approx \frac{6}{\sqrt{M}}$ where $H_{1}$ is the initial water thickness. The first step is to ascertain the convergence of the measurements. We investigated that convergence on the mean chord $C_{10}$ which is a quantity directly yielded by the optical probe. A typical evolution of the mean chord with number of drops considered is plotted in figure 7 . As shown by this figure, the mean chord value converges but still exhibits some fluctuation even when the number of drops becomes large. For different gas velocities, we quantified the minimum number of drops that yields a maximum uncertainty of $3 \%$ (dashed line) on 

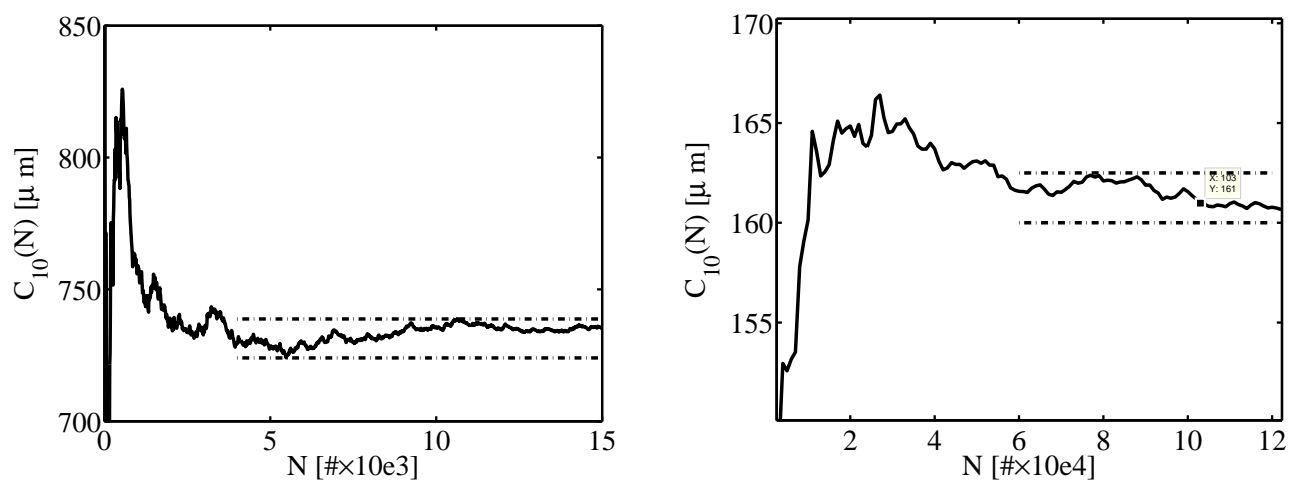

Figure 7. Convergence of mean chord for $U_{g}=30 \mathrm{~m} \cdot \mathrm{s}^{-1}$ (a) and $U_{g}=90 \mathrm{~m} \cdot \mathrm{s}^{-1}$ at $M=16$

$C_{10}$ measurements. For $U_{g}=20 \mathrm{~m} . \mathrm{s}^{-1}$, a minimum of 3000 drops is needed to ensure correspond a convergence of the $C_{10}$ within $3 \%$. For a gas velocity of $90 \mathrm{~m} . \mathrm{s}^{-1}, 40000$ drops correspond to a $1.5 \%$ uncertainty on the mean chord. Table 1 provides the mean chords detected for gas velocities evolving between 20 and $35 \mathrm{~m} . \mathrm{s}^{-1}$ and for three values of the $M$ parameter, namely 1.5, 2 and 4. It happens that for a given gas velocity, a variation in the $M$ parameter changes the mean chord by an amount varying between $20 \%$ and $60 \%$, a low $M$ always leading to the largest drops. To discuss more precisely this influence, we first introduce a mean chord $C_{10}(98 \%)$ obtained by removing $2 \%$ of the largest chords. The interest of such a filtering is because a few large drops are detected, and it is important to evaluate their relative contribution to the mean. Such a $2 \%$ cut-off level was also used by Hong for the analysis of the data collected at $M=16$. According to the data in 1, the maximum

Table 1

Mean value of chord length $C_{10}[\mu m]$ for $M=4 M=2 M=1,5$

\begin{tabular}{|r|c|c|c|c|c|c|c|c|c|c|c|c|}
\hline$U_{g}$ & 20 & 20 & 20 & 25 & 25 & 25 & 30 & 30 & 30 & 35 & 35 & 35 \\
\hline$U_{l}$ & 0.37 & 0.52 & 0.61 & 0.42 & 0.61 & 0.69 & 0.50 & 0.71 & 0.85 & 0.58 & 0.85 & 0.93 \\
\hline$M$ & 3.4 & 1.66 & 1.25 & 4.06 & 1.96 & 1.53 & 4.15 & 2.05 & 1.46 & 4.21 & 1.99 & 1.57 \\
\hline$C_{10}$ & 521.8 & 736.9 & 853.6 & 305.1 & 351.6 & 375.4 & 235.3 & 300.0 & 327.0 & 163.2 & 228.5 & 265.0 \\
\hline$C_{10}(98 \%)$ & 472.2 & 663.5 & 759.4 & 267.7 & 310.8 & 332.2 & 205.2 & 259.0 & 281.3 & 139.6 & 192.3 & 222.6 \\
\hline
\end{tabular}

difference between the true mean chord $C_{10}$ and the filtered mean $C_{10}(98 \%)$ is about $15 \%$. In addition, that difference is larger at high $U_{g}$. Indeed, as $U_{g}$ increases drops are smaller, so that the suppression of even a small amount of large drops has an important impact on the mean chord. These considerations bring to light the influence of large drops and isolated events on $C_{10}$. To investigate this influence, the evolution of $C_{10}$ as a function of $U_{g}$ is plotted Figure 8 for different cut-off values and for the $M=4$ set. As expected, the first $02 \%$ of eliminated chords ( + series ) have more influence on the $C_{1} 0$ than the following cut-offs. This is particularly true at low $U_{g}$. ? This result clearly indicates that the mean chord is affected by a few rare events, and that removing $2 \%$ of these stabilizes the drop size.

On that basis, and as shown figure 8 , it happens that, for a given $U_{g}$, the 


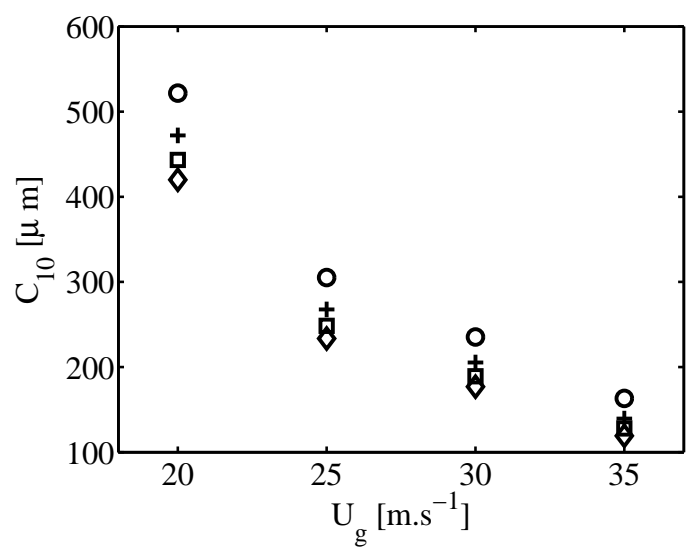

Figure 8. Variations of $C_{10}$ as a function of $U_{g}$ for different cut-off values for $M=4$ set: $\circ=00 \%,+=02 \%, \square=04 \%$ and $\diamond=06 \%$

influence of the M parameter on the average chord is significant although not drastic. Its effect is somewhat pronounced between $M=1.5$ and 2, while the data sets for $M=2$ and $M=4$ provide nearly the same mean drop size.

Now, we can further test whether the available scaling for the mean drop size. That scaling was grounded on the following arguments. First, the experiments of Marmottant (2004) and Marmottant and Villermaux (2004) demonstrated that the mean droplet diameter is proportional to the wavelength of the transverse instability. Second, that transverse wavelength was estimated by Hong et al. 2002 [9], Varga et al 2003, Ben Rayana et al. 2006 by considering the axial acceleration of wave crest by the air stream and the ensuing Rayleigh-Taylor instability. Third, it was further assumed that the fraction of the wave crest which is atomized is proportional to the axial wavelength, namely $=\alpha \lambda_{a x i}$ where $\lambda_{a x i}$ is given by $C_{a x i} \sqrt{\rho_{g} / \rho_{l}} \delta_{g}$. This model leads to:

$$
\lambda_{T}=2 \pi \sqrt{\frac{6 \alpha \cdot C_{a x i}}{C_{d}}} \delta_{G}\left(\frac{\rho_{l}}{\rho_{g}}\right)^{1 / 4}\left(\frac{\rho_{G}\left(U_{G}-U_{C}\right)^{2} \delta_{G}}{\sigma}\right)^{-1 / 2}
$$

$\lambda_{T} \propto \delta_{G}\left(\frac{\rho_{l}}{\rho_{g}}\right)^{1 / 4} W e_{\delta}^{-1 / 2}$ where the drag coefficient $C_{d}$ is about 2. That model predicts a non dimensional drop size $D$ evolving as $W e^{-1 / 2}$. Such a trend was confirmed by previous experiments performed at $M=16$ : the diamond series in figure 4 are the results of Ben Rayana ([5] collected with another optical probe with a sensitive length about $30 \mu \mathrm{m})$.

To report our data collected at low $\mathrm{M}$ on this plot, the Sauter mean diameter $D_{32}$ is directly estimated from the $C_{10}$ using $D_{32}=(3 / 2) C_{10}$ [11]. The drop sizes measured at low $\mathrm{M}$ happen to reasonably agree with the predicted trend, except at the lowest gas velocities for which extra mechanisms alter the ligament formation (see Ben Rayana et al 2006). Besides, the figures are quite 

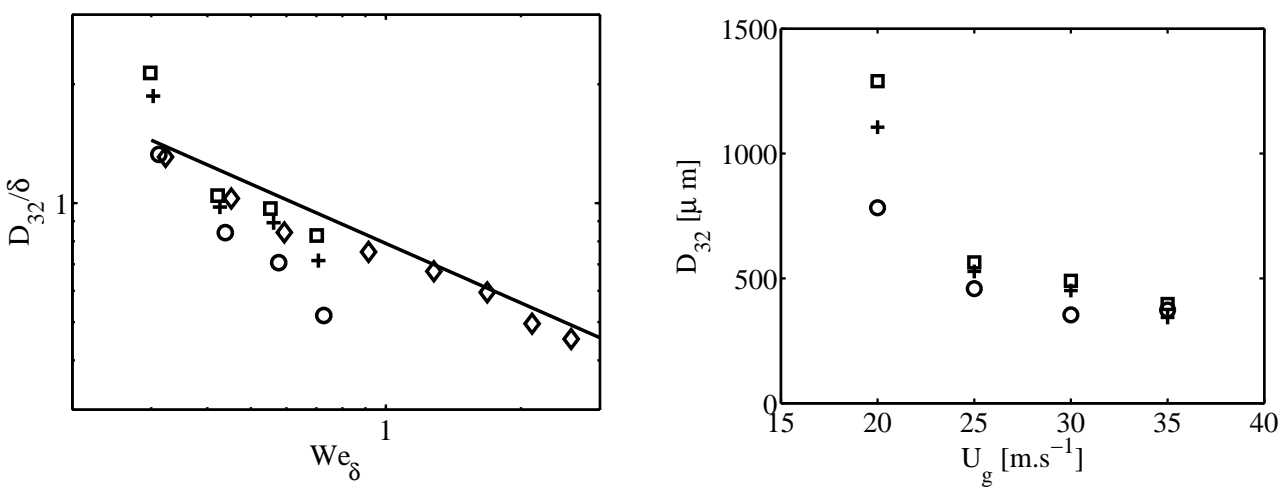

Figure 9. Dimensionless $D_{32}$ as a function of Weber number (a) and a focus on $D_{32}$ data (b): $\diamond=M 16 ; \circ=M 4 ;+=M 2 ; \square=M 1.5$.

close indicating that the prefactor in equation 5 is only slightly modified when $M$ is varied. Since this prefactor includes the fraction $\alpha$ of the crest that is stripped off the bulk liquid, that results indicate that the shape of the axial waves remain rather similar for all $M$.

To further confirm the above mentioned trends and more precisely investigate the influence of $\mathrm{M}$, more results at low $\mathrm{M}$ and at higher gas velocity are needed: such a campaign requires some adaptation of the existing experiment. Finally, let us consider the volumetric flux $J_{L}$ of the droplet produced by stripping. That flux corresponds to the entrainment velocity $U_{e}$ at the interface. The latter can be estimated (Ben Rayana [5]) by writing down the continuity of the turbulent stress at the interface, namely:

$$
\rho_{L} U_{e}^{2}=C_{1} \rho_{G} u^{\prime 2}
$$

where is $u^{\prime 2}$ the turbulent intensity in the gas phase and $C_{1}$ an entrainment coefficient. As in a single phase mixing layer, the velocity fluctuation is estimated to be proportional to the mean velocity difference along: $u^{\prime}=\beta\left(U_{g}-U_{l}\right)$. The volumetric flux $J_{L}$ is then given by:

$$
J_{L}=C_{1}^{1 / 2}\left(\frac{\rho_{g}}{\rho_{l}}\right)^{1 / 2}\left(\beta\left(U_{g}-U_{l}\right)\right)
$$

This simple model predicts $J_{L}$ to increase as $U_{g}-U_{l}$. As shown on figure 4, that trend is recovered for all the experimental conditions considered except at the lowest gas velocities. The diamond series (Ben Rayana's data at $\mathrm{M}=16$ ) corresponds to the straight line $J_{L}=\left(U_{g}-U_{l}-15\right) \times 0.0013$, where the -15 shift models the absence of atomisation below about $15 \mathrm{~m} . \mathrm{s}^{-1}$. Its slope 0.0013 allows to evaluate an entrainment coefficient $C_{1}$ equal to 0.013 for $\beta$ equal to 0.35, avalue measured from particule image velocity by Descamps et al. [10] This small value for a single phase mixing layer $\left(C_{1} \approx 0.25\right)$ is attributed to the fact that the measure is here localized. In experiment with strong spatial 

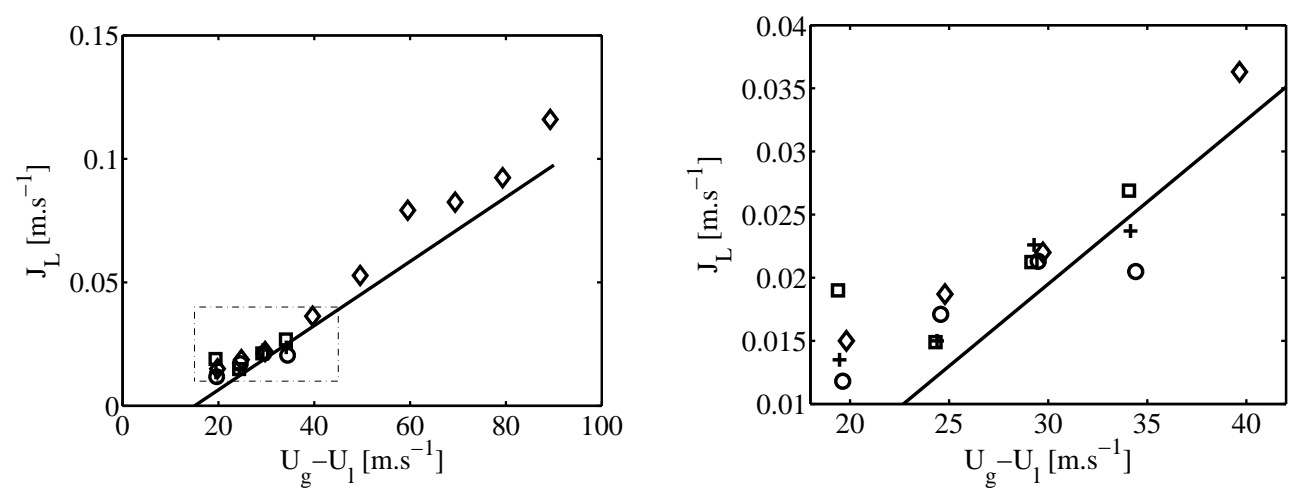

Figure 10. Volumetric flux $J_{L}$ as a function of $U_{g}-U_{l}$ (a) and a focus on low $M$ data (b): $\diamond=M 16 \circ=M 4 ;+=M 2 ; \square=M 1.5$

gradiants, local data cannot be directly compared with a global entrainment rate.

\section{Chord pdf}

The last step is to check how chord distributions are modified when $M$ is varied for fixed $U_{g}$. Figure 5 is a superposition of the distributions of $C / C_{10}$ for three values of $M$, for the same $U_{g}$ : all three pdfs are well superposed. The

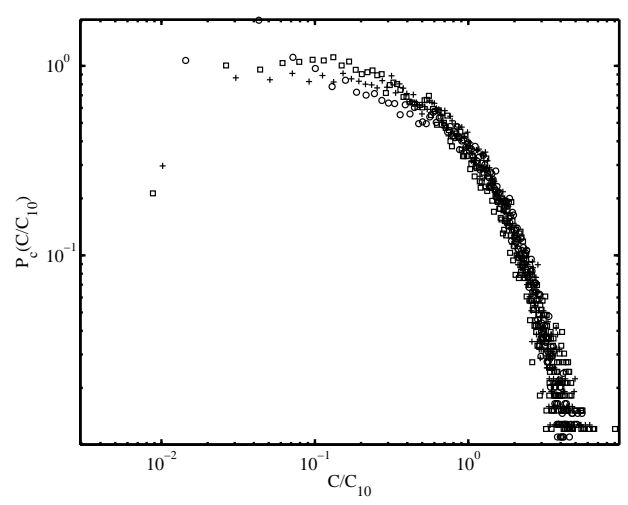

Figure 11. Dimensionless pdf of chord for $U_{g}=20 \mathrm{~m} \cdot \mathrm{s}^{-1}$ at three different $M$ : $\circ=M 4 ;+=M 2 ; \square=M 1.5$

standard deviation of these pdfs, defined as $\sigma_{C}=\sqrt{C_{20} / C_{10}^{2}-1}$, are given on table 2: $\sigma_{C}$ increases with $U_{g}$, but it is roughly constant when $M$ is varied for a fixed $U_{g}$. Chord distributions are therefore mainly controlled by $U_{g}$.

Table 2

Root mean square of dimensionless chord for $M=4,2$ and 1.5

\begin{tabular}{|r|c|c|c|c|c|c|c|c|c|c|c|c|}
\hline$U_{g}$ & 20 & 20 & 20 & 25 & 25 & 25 & 30 & 30 & 30 & 35 & 35 & 35 \\
\hline$\sigma\left(C / C_{10}\right)$ & 1.09 & 1.09 & 1.19 & 1.27 & 1.24 & 1.20 & 1.29 & 1.39 & 1.39 & 1.46 & 1.53 & 1.53 \\
\hline
\end{tabular}




\section{Conclusion}

We have carried out frequency and spatial growthrate measurements for the shear instability of a planar two-phase mixing layer. Experimental frequencies were found to agree with the prediction of a linear stability analysis including a velocity deficit at the interface, while experimental growthrates were much larger than predicted, and exhibited a dependence on $U_{g}$ not predicted by the analysis. Droplet size measurements were carried out with an optical probe. Drop chord and volumic flux follow the scaling law predicted by known mechanisms, in particular $D_{32} \sim W e^{-1 / 2}$. Additional data for larger $U_{g}$ for the same $M$ are needed to confirm these results.

\section{References}

[1] L. Raynal, "Instabilité et entrainement à l'interface d'une couche de mélange liquide-gaz", Thèse UJF, LEGI (1997).

[2] P.Marmottant and E. Villermaux, "On Spray Formation", J.Fluid Mech.,498, 73 (2004).

[3] M. Hong, "Atomisation et mélange dans les jets coaxiaux Liquide-gaz", Thèse INPG, LEGI (2003).

[4] P.E. Dimotakis, "Two-Dimensional Shear-Layer Entrainment" AIAA J. 24 1791-1796 (1986).

[5] F. Ben Rayana, "Contribution à l'étude des instabilités interfaciales liquide-gaz en atomisation assistée et tailles de gouttes", Thèse INPG, LEGI (2007).

[6] J.P. Matas, S. Marty, A. Cartellier, "Experimental and analytical study of a shear instability of a gaz-liquid mixing layer" , Physic of fluid vol. 23, (2011).

[7] A. Cartellier, F. Ben Rayana, "Dispersed phase measurements in sprays using optical probes", 3rd International Symposium on Two-Phase Flow Modelling and Experimentation (Pisa, 22-24 September 2004).

[8] M. Hong, A. Cartellier, E Hopfinger, "Characterization of phase detection optical probes for the measurement of the dispersed phase parameters in sprays", International Journal of Multiphase Flow (2004).

[9] M. Hong ,A. Cartellier ,E. Hopfinger , Atomisation and mixing in coaxial injection, Proc. 4th Int. Conference on Launcher Technology "Space Launcher Liquid Propulsion", Liège, Belgique, 3-6 Déc. (2002).

[10] M.N. Descamps, J.-P. Matas, A. Cartellier, "Gas-liquid atomisation: gas phase characteristics by PIV measurements and spatial evolution of the spray", 2nd Colloque INCA 23-24 Octobre 2008

[11] W.Liu and N.N. Clark, "Relationships between distributions of chord lengths and distributions of bubble sizes including their statistical parameter", Int. J. Multiphase Flow., 21 6, 1073-1089 (1995). 